\title{
Posttraumatic Stress Symptoms in Preschool Children in Foster Care: The Influence of Placement and Foster Family Environment
}

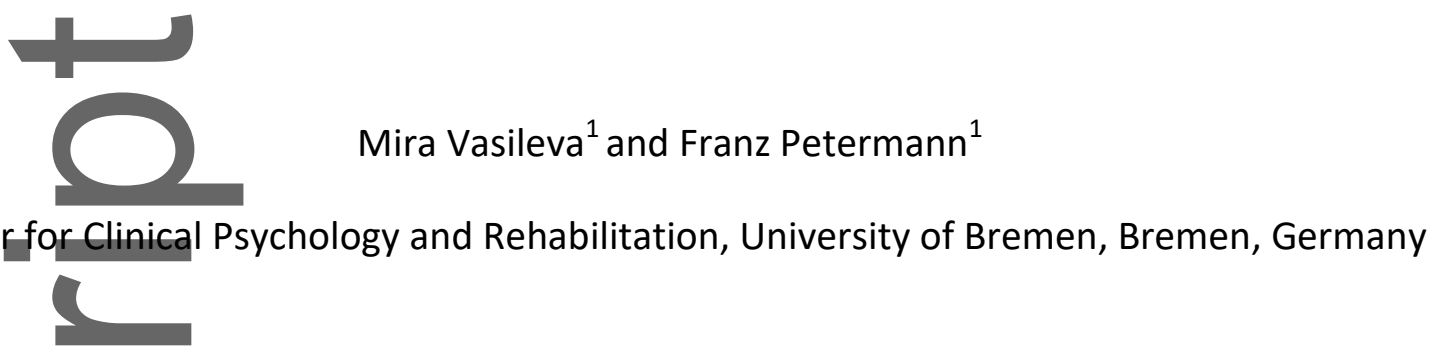

${ }^{1}$ Center for Clinical Psychology and Rehabilitation, University of Bremen, Bremen, Germany

Correspondence concerning this article should be addressed to Mira Vasileva, Center for Clinical Psychology and Rehabilitation, University of Bremen, Grazer Str. 6, 28359 Bremen, Germany.E-mail: mvasileva@uni-bremen.de

Copyright (c) 2017 International Society for Traumatic Stress Studies. View this article online at wileyonlinelibrary.com

DOI: $10.1002 /$ jts.22217
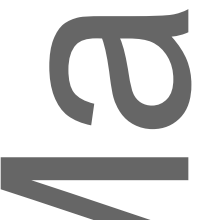

Children in foster care often experience traumatic events which increase their risk for posttraumatic stress symptoms (PTSS). Until now, no research has investigated the developmentally sensitive PTSS criteria for preschoolers among children in foster care. The current study estimated the prevalence of potentially traumatic experiences and clinical PTSS in German foster care children aged 3 to 7 years. The foster parents of 324 children completed questionnaires about children's PTSS, foster parental stress, parenting, and family functioning. Linear regression models tested trauma-related variables, placement history, and foster family as predictors of PTSS. Approximately $45.4 \%$ of the foster children had experienced at least one traumatic event and $15.4 \%$ had clinical PTSS. Physical abuse, $\beta=.34, p<.001$; hospitalization, $\beta=-.17, p=.026$; witnessing someone being hurt, $\beta=-.15$, $p=.047$; and parental stress, $\beta=.43, p<.001$, were significantly associated with PTSS.

Results demonstrate the impact of the foster family when children cope with trauma and

is is he author manuscript accepted for publication and has undergone full peer review but has not been thr he copyediting, typesetting, pagination and proofreading process, which may lead to differences between this version and the Version of Record. Please cite this article as doi: $\underline{10.1002 / j \text { ts. } 22217 .}$.

This article is protected by copyright. All rights reserved. 
suggest the necessity of trauma-sensitive trainings for foster parents with stress management as an important component.

In 2013, the Diagnostic and Statistical Manual of Mental Disorders (5th ed.; DSM-5; American Psychiatric Association [APA], 2013) included for the first time diagnostic criteria for posttraumatic stress disorder (PTSD) for children aged six years and younger Although the symptoms are the same as for older children and adolescents, they could manifest differently in younger children (Rousseau, 2015). Young children often express their recollections as play reenactments and rarely show symptoms of avoidance in an obvious way. Furthermore, since preschool children have limited verbal capacities, symptoms should be rated by their caregivers. This implies an adapted diagnostic approach because caregivers cannot properly provide information about the child's thoughts and feelings (Scheeringa, 2011).

The newly added diagnosis of PTSD for preschool children is the result of long-standing research on the validity of developmentally sensitive diagnostic criteria (Scheeringa, Zeanah, Drell, \& Larrieu, 1995). Studies have already tested developmentally adjusted symptoms in preschool children who had experienced an accidental traumatic event (Graf, Schiestl, \& Landolt, 2011), life-threatening illness (Graf, Bergstraesser, \& Landolt, 2013), natural disaster (Scheeringa \& Zeanah, 2008), or intimate partner violence (Levendosky, Bogat, \& Martinez-Torteya, 2013). The PTSD prevalence using the alternative criteria ranged between $4 \%$ (children witnessing intimate partner violence; Levendosky et al., 2013) and 50\% (victims of Hurricane Katrina; Scheeringa \& Zeanah, 2008). As yet, no scientific knowledge exists about posttraumatic stress symptoms (PTSS) in the vulnerable population of preschool children in foster care. They have often experienced traumatic events prior to their placement (most commonly physical abuse; Vasileva \& Petermann, 2016) which suggests a high prevalence of PTSS. They are also exposed to the specific impact of placement conditions and of the new foster family, which may influence the way they cope with trauma.

Influence of Placement and Foster Family Characteristics on Children's Mental Health Theoretical and empirical data on foster children's mental health combine evidence from developmental psychopathology models for children exposed to traumatic events (e.g., for maltreated or deprived children) and the specific challenges children face living in foster care (Tarren-Sweeney, 2008). Foster children's behavioral and emotional problems are associated with pre-placement experiences as well as "in care" circumstances (i.e., placement history and foster family characteristics; Orme \& Buehler, 2001). Foster care is usually a temporary step aiming at reunifying the child with the biological parents. 
Therefore, parent visitations are planned in order to maintain the relationship of the child with the biological family. Such visitations can sometimes trigger reminders of traumatic experiences and be stressful for the child. In this context, some foster parents report temporary worsening of children's emotional state and behavior (Haight, Kagle, \& Black, 2003). Further placement predictors for children's psychological problems are, for instance, placement after the first six months of life, placement insecurity (i.e., frequent placement change), and nonkinship foster care (Goemans, van Geel, \& Vedder, 2016; Tarren-Sweeney, 2008).

Alongside placement characteristics, researchers and clinicians acknowledge the role of the new foster family environment on the mental health of children in foster care (Dozier, Zeanah, \&Bernard, 2013). Orme and Buehler (2001) reviewed the literature on foster family characteristics and discussed foster parental stress and parenting practices as well as poor family functioning as familial predictors for foster children's behavioral and emotional problems. Recent evidence also confirms this association. Vanderfaeillie, Van Holen, Vanschoonlandt, Robberechts, and Stroobants (2013) reported that school-aged children exhibited more mental health problems when their foster parents experienced high levels of stress and when they used more negative parenting strategies. For preschool children, there was also an association between foster parents' and children's stress levels measured with biological markers (Van Andel et al., 2015). There is, however, no knowledge about the impact of the foster family particularly on children's PTSS. A review of the literature on familial predictors in nonfoster populations indicates that parental stress, parenting, and family relations are associated not only with general mental health problems but also with PTSS (Grafet al., 2011; Scheeringa, Myers, Putnam, \& Zeanah, 2015).

It should, of course, be acknowledged that there is reciprocity between children's and foster parents' mental health. Taking care of a traumatized child who shows difficulties in different areas could be a challenge for the foster parents and may elevate their stress levels and need for more support (Murray, Tarren-Sweeney, \& France, 2011).

The Current Study

Overall, there are no studies on PTSS in preschool children in foster care. It is of interest if placement and foster family characteristics, assumed to be associated with children's mental health, have an impact particularly on children's PTSS. Such information can help derive implications for social and clinical practice. Hence, the current study has two objectives. First, we sought to estimate the prevalence of potentially traumatic experiences and clinically relevant PTSS in preschool children in foster care in Germany and to describe their distributions. In Germany, there are approximately 600 governmental and private 
welfare agencies that organize their work with foster children and families in different ways. Few agencies include mental health diagnostics, so it is unclear as to how many children need therapeutic treatment. Because foster children have often experienced interpersonal trauma and come from high-risk environments, we expect higher frequencies than in German-speaking preschool children with other trauma types who live with their biological parents (13\%; Graf et al., 2011). Second, the current study examined whether placement and fosten family characteristics predicted PTSS in preschool children in foster care. In particular, we tested the hypothesis that placement characteristics (i.e., more contacts with the biological parents, early age at first placement, longer duration of current care, and many placement changes), foster parental stress, dysfunctional parenting, and poor family functioning would predict increased PTSS in children who experienced a traumatic event.

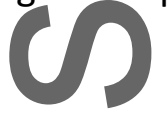

Method

Participants and Procedure

Data were collected between March 2015 and March 2016 by contacting nearly 600 statewide governmental welfare agencies and 130 private child welfare agencies or self-help organizations, as well as password-protected forums for foster parents. Welfare agencies were first contacted via e-mail and then, if there was no response, via telephone. A total of 85 child welfare agencies refused to participate and 17 could not be reached. Foster parents $(N=382)$ from approximately 210 child welfare agencies took part in the study. The rest of the agencies had ho children that fulfilled the inclusion criteria, could not persuade the foster parents to participate, or did not forward the information despite agreeing to participate. Because information about the study was routed through to the foster parents by the welfare agencies, the response rate of foster parents could not be clarified. Children were eligible for the study if (a) they were in long-term foster care; (b) had no diagnosed autism spectrum disorder; and (c) had not experienced any traumatic events in the past month (one criterion for PTSD is that the symptoms last over a month; APA, 2013). The foster parents completed online $(n=308)$ or paper-and-pencil $(n=74)$ questionnaires. Parents who answered questions online reported more dysfunctional parenting, $t(321)=-4.43, p<.001$. There were no differences between the online and offline answers for all other variables of interest (all $p s=.064$ to .632). Of 382 eligible foster parents who agreed to participate in the study, we included these who answered at least $90 \%$ of the questions about children's PTSS. There were no differences between participants $(n=324)$ and nonparticipants $(n=58)$ with regard to gender, age, immigration status, type and number of children's different traumatic experiences, duration of current care, and age at first placement (all $t$ tests and chi-square tests had a significance level between $p=.148$ and 
$p=.896)$. The study was approved by the ethics commission of the University of Bremen (Bremen, Germany).

The final sample consisted of children with a mean age of $M=58.65$ months ( $S D=15.51$ ); $49.7 \%$ ( $n=159$ ) were boys. Table 1 gives an overview of sample characteristics with valid percentages excluding missing demographic data. The children had been initially removed from their biological families at mean age 13.21 months $(S D=14.84)$. Most $(77.9 \%, n=151)$ had been visited by their biological parents once a month or less. Foster parents who completed the questionnaires were mostly female $(81.4 \%, n=258)$, with a mean age of $49.42(S D=7.28)$ years. Only 27 children (8.4 \%) lived with relatives.

To analyze the current sample's representativity, demographic variables were compared with corresponding data of the German Statistical Federal Office (Statistisches Bundesamt, 2016). The last report describes children aged 3 to 6 years who were in long-term foster care at the end of 2014 ( $N=10,919 ; 51.5 \%$ boys, $18.9 \%$ immigrant background, $12.2 \%$ kinship foster care). The current sample represents about $3 \%$ of the foster care population in this age group. There were no differences in gender, $\chi^{2}(1)=0.22, p=.639$, and immigrant background, $\chi^{2}(1)=3.79, p=.051$, between the current and reference samples. Although children in kinship foster care were the minority in both samples, these children were slightly underrepresented in the current sample, $\chi^{2}(1)=4.33, p=.038$.

Measures

Traumatic Events and PTSS. Potentially traumatic events across the child's lifespan and PTSS according to DSM-5 were assessed with the German translation of the Young Child PTSD Checklist (YCPC; Landolt \& Haag, 2014; Scheeringa, 2013). Parents were instructed that an event is traumatic when the child (a) felt that she or he might die or (b) had or felt like she or he might get a serious injury, or (c) saw (a) and (b) happen to another person or saw someone die. The 11 potentially traumatic experiences were used to define binary variables: accident, attack by an animal, man-made disaster, natural disaster, hospitalization or invasive medical procedure, physical abuse, sexual abuse, accidental burning, near drowning, witnessing another person being hurt, and kidnapping.

The YCPC also asked 23 questions on children's PTSS. There were 18 symptoms derived from $D S M-5$. These comprised eight items assessing reexperiencing, six items assessing avoidance/negative alterations in cognition and mood, and five items assessing arousal. Five extra symptoms beyond $D S M-5$ were included based on evidence that these symptoms are often observed in young children after traumatic exposure (e.g., expression of physical aggression after the traumatic event; Scheeringa, Zeanah, Myers, \& Putnam, 2003). A total score was calculated as the sum of the scores of these items and of the DSM-5 symptoms. 
Foster parents rated the children's symptoms on a 5-point Likert scale (from $0=$ not at all to 4 = every day) so that the total score ranged from 0 to 92.

The attention cut-offs (total $=12$, reexperiencing $=4$, avoidance/negative alterations in cognition and mood $=2$, increased arousal $=4$ ) were used to identify children with symptoms and functional impairment and who may need treatment but do not have enough symptoms for a diagnosis. The clinical scores for PTSS were derived from the diagnosis cut-offs (total $=26$, reexperiencing $=8$, avoidance/negative alterations in cognition and $\operatorname{mood}=4$, increased arousal $=10$ ) and by looking at the symptom combinations according to DSM-5. To be suspected of having a PTSD according to DSM-5, a symptom was considered as fulfilled if a score of 2 = two to four times a week/half of the time was reported and the clinical cut-off $=4$ for function impairment was exceeded.

The interview form with the YCPC questions showed excellent test-retest reliability and external validity (Scheeringa, Myers, Putnam, \& Zeanah, 2012). In the current sample, all three symptom clusters showed acceptable internal consistency when tested on children who have experienced potentially traumatic events ( $n=147$; reexperiencing, Cronbach's aplha = .81, avoidance/negative alterations in cognition and mood, Cronbach's alpha = .79; and arousal, Cronbach's alpha $=.79)$. Because foster parents sometimes do not get all the information about a child they host, the end of the questionnaire asked whether or not they thought they had enough information about the foster child to answer the previous questions.

Placement History. Foster parents were asked about the age at which the child had been initially moved from the biological parents, the number of placements the child had experienced since then, how long the child had been in the current foster family, and how many contacts the child had had with the biological parents. Answers to these questions were used to calculate continuous variables for the analysis.

Parenting. The 28-item German version of the Parenting Scale was used to estimate parenting practices in disciplinary situations (Arnold, O'Leary, Wolff, \& Acker, 1993; Naumann et al., 2010). Foster parents chose between two options along a 7-point Likert scale from 1 to 7 regarding specific disciplinary strategies-overreactivity (e.g., "When my child misbehaves ... I rarely use bad language or curse/I almost always use bad language"); laxness (e.g., "If my child gets upset when I say 'no' ... I stick to what I said/I back down and give in to my child"); and verbosity (e.g., "When I tell my child not to do something ... I say very little/I say a lot"). The total score ranged from 28 to 196 with higher scores of this continuous variable representing more dysfunctional parenting. Naumann et al. (2010) reported on the good reliability and validity of the German version for parents of 
kindergarten children. There was good internal consistency, and Cronbach's alpha was .82 in the current sample.

Foster Rarents' Stress. Parental stress was assessed with the stress scale of the Parental Stress Questionnaire (Domsch \& Lohaus, 2010). In 17 items, foster parents indicated, using a four-point Likert scale (from $0=$ strongly agree to $3=$ strongly disagree), the stress they experience in the interaction with the child and in everyday hassles as parents (e.g., "I don't feel ready for some tasks as a parent"). Foster parental stress was used as a continuous variable (range of scores between 0 and 51) with higher scores representing higher stress level. Reliability, calculated using Cronbach's alpha, for this instrument's scales ranges from .76 and .92 (Domsch \& Lohaus, 2010). In the current sample, internal consistency for the stress scale was excellent (Cronbach's alpha $=.93$ ).

Family Functioning. The quality of the foster family environment was measured using the general functioning scale of the McMaster's Family Assessment Device (Epstein, Baldwin, \& Bishop, 1983). The scale assesses the functioning of the family as an interactional system that can influence the behavior of family members using 12 items (e.g., "In times of crisis we can turn to each other for support") on a 4-point Likert scale (from $1=$ strongly agree to $4=$ strongly disagree). The mean score of the general functioning scale was included as a continuous variable (range of mean scores between 1 and 4) in the analysis, with higher scores indicating better family functioning. Reliability and validity of the scale were confirmed-in previous research (Boterhoven de Haan, Hafekost, Lawrence, Sawyer, \& Zubrick, 2015). The internal consistency (Cronbach's alpha $=.77$ ) was acceptable in the current sample.

Data Analysis

All statistical analyses were conducted using IBM SPSS 22 (IBM Corp., Armonk, NY) and the norm 2 package in $\mathrm{R}$ (version 2.01). Missing values (17.6\% of the values in the variables of interest) were imputed through the predictive mean matching method for multiple imputations in SPSS (10 imputations, 200 Markov chain Monte Carlo [MCMC] iterations) using traumatic experiences as the covariate (Scheeringa et al., 2015). This method is regression-based and imputes missing values of one respondent from another respondent who has the closest predicted values. Pooled estimates of the imputations were calculated in R (Barnard \& Rubin, 1999).

Descriptive statistics were calculated to describe the distributions of potentially traumatic experiences and PTSS. The impact of parents' confidence in answering questions about the child was compared using chi-square and $t$ tests. Given that PTSS develop following traumatic events, predictors of PTSS were examined for those children who had faced 
potentially traumatic experiences. First, Spearman's correlations were calculated to investigate possible single predictors. Predictors were derived from evidences about their association with mental health of children in foster care. Therefore, the study has an exploratory character. In order to identify the set of predictors that best explained the most variance of the PTSS, all possible regression models with the 12 predictors were investigated. The final model was selected based on the comparison of adjusted $R^{2}$, the root mean square error, and Akaike's information criterion (Akaike, 1974). Standard errors for conducting inferential tests were assessed using 1,000 bootstrap samples. Changes in the relation between variables in the single-predictor analyses and in the multiple analysis were monitored and possible interactions or indirect effects that could explain the mechanisms behind such changes were tested using the PROCESS macro (Heyes, 2013). For all tests, $p<.05$ was considered significant.

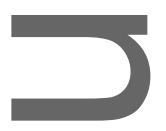

Results

Potentially Traumatic Events and PTSS

For almost half of the children, foster parents reported knowledge of potentially traumatic experiences $(45.4 \%, n=147)$. The most frequent experiences were physical abuse and hospitalization or invasive medical procedure (Table 1). Children with traumatic exposures had experienced between one and five different types of potentially traumatic events (e.g., physical abuse and hospitalization). Most, however, had experienced one $(57.1 \%, n=84)$ or two $(27.9 \%, n=41)$ types. The most common combinations were physical abuse and hospitalization ( $n=15$ ) as well as physical abuse and witnessing somebody being hurt $(n=13)$.

Mean scores of specific and total PTSS in the overall sample were nearly as high as the attention cut-offs (Table 2). The distribution of PTSS was assessed for the children who experienced potentially traumatic events. All three symptoms-reexperiencing, avoidance/negative alterations in cognition and mood, and arousal-as well as the overall PTSS, were positively skewed (skewness $=0.71,1.45,0.62,0.74$, respectively) indicating that in most children symptoms were absent or weak. The greatest skewness was calculated for avoidance/negative alterations in cognition and mood; children showed high scores of this symptom cluster less frequently.

When using the YCPC cut-off, 15.4\% $(n=50)$ were classified as having PTSS of clinical relevance. Following the symptom combination in DSM-5, 11.7\% $(n=38)$ children were suspected to have PTSD. In other words, of the foster children who experienced traumatic 
events ( $n=147$ ), $34 \%$ were suspected to have a PTSD diagnosis according to the YCPC cutoff and $25.9 \%$ according to the DSM-5.

About $17 \%$ of the foster parents $(n=55)$ shared that they did not think they had enough information to answer the questions about their foster children. There were no differences in the frequencies of traumatic experiences in general and on specific potential traumatic events between these foster parents and foster parents who felt confident to answer the questions, $\chi^{2}(1, N=299)=0.05$ to $3.02, p s=.082$ to .824 . They reported higher mean rates for children's reexperiencing, $t(300)=2.03, p=.043$, and function impairment, $t(300)=2.03$, $p=.042$. There were no differences when rating the severity of avoidance/negative alterations in cognition and mood, $t(300)=1.42$, arousal, $t(300)=1.69$, and overall PTSS score, $t(300)=1.94$, ( $p s=.053$ to .156$)$. In addition, foster parents who were uncertain regarding the information they had did not differ in classifying the child as having clinical symptoms of reexperiencing, $\chi^{2}(1, N=300)=5.84$; arousal, $\chi^{2}(1, N=300)=5.33$; or suspected PTSD according to the YCPC cut-off, $\chi^{2}(1, N=300)=0.84$, or according to the $D S M-5, \chi^{2}(1, N=301)=1.19$ ( $p s=.054$ to .350$)$. However, through their estimation of the children's symptoms, children were more frequently clustered as having clinical symptoms of avoidance/negative alterations in cognition and mood, $\chi^{2}(2)=6.64, p=.036$. If these foster parents were excluded, around $15.1 \%(n=37)$ still had scores above the YCPC cut-off and $11.4 \%(n=34)$ had a suspected PTSD according to the DSM-5.

\section{Predictors of PTSS}

Predictors of PTSS severity were tested only with children with potentially traumatic experiences $(n=147)$. In the single-predictor analysis, physical abuse, age at first placement, and higher foster parental stress level correlated positively with higher PTSS (Table 3). Hospitalization and duration of the current care were associated with lower PTSS. Some trauma types (accident, man-made disasters, natural disasters, accidental burning, near drowning, and kidnapping) were not included as possible predictors because less than five children had experienced them, indicating that inclusion would hinder calculation of the test statistics or their interpretation.

Comparing Akaike's information criteria indicated a model with five predictors (physical abuse, hospitalization, witnessing others being hurt, foster parent's stress, and parenting). Including further variables resulted in only slight changes of the information criterion from 0.5 . This modet had adjusted $R^{2}=0.34$ and root mean square of 12.66 . There was only one model with contacts with the biological parents as additional predictor that explained $0.32 \%$ more variance. However, because this was only a slight difference, we selected the fivepredictor model as the final model (Table 4). 
In the multiple regression analysis, physical abuse predicted more PTSS whereas hospitalization or invasive medical procedures and witnessing another person being hurt were associated with fewer symptoms. Foster parents' stress remained a significant predictor of PTSS. While dysfunctional parenting was not significant in the single-predictor analysis, it was associated with fewer PTSS in the multiple regressions. The final model explained $36 \%$ of the PTSS variance. When comparing the pooled imputed data to the originat sample, standardized $\beta$-coefficients remained nearly equal. However, only physical abuse, $b=10.42, S E=2.54, p<.001$; parental stress, $b=0.61, S E=0.12, p<.001$; and parenting, $b=-0.16, S E=0.08, p=.044$, predicted PTSS significantly in the original sample.

To disentangle why parenting was not a significant single predictor but improved the multivariate model, we tested interactions and indirect effects including parenting and the other variables in the model. Whereas interactions were nonsignificant and did not improve the model, there was an indirect effect of foster parents' stress, $b=-0.10, S E=0.05, p=$ .032 , on PTSS, mediated by parenting. Parenting was selected as the mediator following the suggestion that high parental stress leads to more ineffective parenting (Scheeringa \& Zeanah, 2001). However, this indirect effect and the direct effect of parental stress on PTSS had opposite signs, indicating possible suppression effects (MacKinnon, Krull, \& Lockwood, 2000). In order to identify the potential suppressor variables, each independent variable was systematically extracted from the equation. The effect of parenting was not more significant in the absence of foster parental stress, indicating that parental stress acts as a suppressorvariable increasing the predictive validity of parenting when added in the model (Tzelgov \& Henik, 1991).

\section{Discussion}

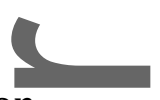

This study gave first insights into the traumatic exposure and PTSS of preschool children in foster care. According to foster parents' knowledge and estimations nearly half of these children experienced some potentially traumatic events and $11.7 \%-15.4 \%$ were suspected to have PTSD. The symptom severity was positively associated with physical abuse and foster parents' stress, whereas hospitalization and witnessing another person being hurt predicted fewer symptoms. There were also some indications that the statistical association between dysfunctional parenting and fewer PTSS is suppressed by foster parents' stress. Children in foster care in the current sample showed lower prevalence of suspected PTSD than older children in foster care in a small German sample (28\%, $N=34$, according to the developmentally sensitive criteria; Rosner, Arnold, Groh, \& Hagl, 2012). These differences can be explained by the high exposure to potentially traumatic experiences in the older 
sample (92\%), compared to the current sample (45\%). Furthermore, Rosner et al. (2012) used a clinical interview with the children. Due to the children's limited language capacities, the current analysis uses their foster parents' responses. Foster parents, however, may lack information about the child's biography, which could also explain the reports of lower exposure to potentially traumatic experiences in the current sample. Additionally, younger children still develop their cognitive skills and lack previous information. Hence, they may understand the traumatic event in different, less overwhelming ways or process and memorize it differently than older children and adolescence (Graf et al., 2013; Scheeringa et al., 1995).

As expected, children in foster care more frequently (34\%) showed symptoms of clinical relevance after experiencing potentially traumatic events than children with burns (13\%; Graf et al.,2011). This could be the result of the high exposure to interpersonal traumatic experiences of the children in foster care. In a meta-analysis of predictors for PTSD, Alisic et al. (2014) found the highest rates of PTSD in children exposed to interpersonal trauma. Interpersonal traumatic experiences can cause dysfunctional interaction patterns when the perpetrator is one of the parents (Hesse \& Main, 2000) or, as studies with older children and adults show, cause maladaptive cognitive appraisals that can influence the way a child develops and copes with PTSS (Meiser-Stedman, Dalgleish, Glucksman, Yule, \& Smith, 2009). However, foster children and children who experience interpersonal trauma have been exposed to further risks, even before the trauma, which makes them more vulnerable than populations with non-interpersonal traumatic experiences (Enlow, Blood, \& Egeland, 2013).

Additionally, we explored potential predictors of PTSS. In accordance with previous studies, physical abuse was associated with higher PTSS (Grasso et al., 2009). On the contrary, hospitalization and witnessing another person being hurt predicted less PTSS. Here it is important to note that children with these traumatic experiences were not compared to children without trauma exposure but to children who experienced other trauma types. In other words, hospitalization, which is a non-interpersonal traumatic event, was compared to mainly interpersonal traumatic events. In the same way, witnessing others being hurt was compared to trauma types indicating victimization. On the one hand, this evidence could support the higher risk potential of interpersonal trauma and victimization for PTSS toward non-interpersonal trauma and witnessing others being hurt (Alisic et al., 2014; Kulkarni, Graham-Bermann, Rauch, \& Seng, 2011; Tagay et al., 2013). On the other hand, when interpreting these results, it should be acknowledged that children's traumatic experiences were rated by their foster parents. It remains unclear if the child experienced as lifethreatening a hospitalization or an invasive medical procedure reported by the foster parents. In the same way, foster parents could only suppose if the child thought a person might be seriously injured or die when witnessing, for example, violence in the biological 
family. This could have led to including experiences in the analysis that were not traumatic for the child and have, therefore, less impact on PTSS than other trauma types.

Although placement characteristics, such as age at first placement and duration of the current care, were significantly associated with PTSS in the single-predictor analysis, they did not improve the model including trauma- and family-related predictors. This could be related to the fact that young age at first placement and, therefore, longer duration of the current care prevent the child experiencing further adversities in the biological family (Tarren-Sweeney, 2008). In the current study, age at first placement as well as duration of the current care correlated with all trauma types.

Furthermore, children of foster parents experiencing higher stress levels showed more PTSS. On the one hand, foster parents' stress could decrease their sensitivity towards the children's needs and their availability in the interaction with the child; these are key characteristics that help children build their regulatory capabilities and decrease their stress levels, which may help them cope with the traumatic experience in better ways (Dozier et al., 2006). On the other hand, children's trauma-related symptoms could represent a difficulty and challenge for the foster parents, which could increase the stress foster parents experience (Murray et al., 2011).

There was also an unexpected negative association between dysfunctional parenting and fewer PTSS that could be explained with the suppression effect of foster parental stress in the current sample. In previous research, parenting was found to be associated with some child outcomes in the aftermath of the traumatic event, such as internalizing (Gewirtz, DeGarmo, \& Medhanie, 2011) and externalizing symptoms (Levendosky, Huth-Bocks, Shapiro, \& Semel, 2003) but did not predict others, such as child-reported depression (Gewirtz et al., 2011) or PTSS (Scheeringa et al., 2015). The current result indicates that foster parents' parenting in disciplinary situations may not be as important for specific PTSS as other aspects of the interaction with the foster child like nurturance, synchrony, and security (Dozier et al., 2013). The possible suppression effect implies that further studies on the effect of parenting should go beyond the investigation of main effects to analyze the underlying mechanisms in order to derive practical implications. Foster parents' stress was a significant predictor and should be considered in further models explaining PTSS. Researchers should, however, be aware that foster parents' stress may suppress other family variables such as parenting.

The present study sought to estimate the prevalence of trauma and clinical PTSS in preschool children in foster care in Germany. Although there were no substantial differences in demographic variables between the current sample and the report of the Statistical Federal Office that could jeopardize the sample's representativity, there still could 
be selective effects in collecting the data. Furthermore, the cross-sectional design hampered analyzing directions and potential mechanisms in the significant relationship of PTSS severity and family characteristics. Data based on self-report could also be biased.

When interpreting the current results, it is inevitable that we discuss to what extent, if any, foster parents are reliable informants. Most of the foster parents in the current sample were thought to have enough information to answer questions about the child's traumatic experiences and PTSS. Even the foster parents that felt they lacked information about the child did not differ in their rating on traumatic experiences or PTSS. Nevertheless, it is difficult forfoster parents to estimate if an event was traumatic for the child. Research findings also show that there are inter-rater differences between foster parents and children or teachers when estimating internalizing and externalizing problems (Strijker, van Oijen, \& Knot-Dickscheit, 2011; Tarren-Sweeney, Hazell, \& Carr, 2004). However, there are still no findings about the inter-rater agreement of foster parents and other informants on PTSS. And yet, they are the current caregivers spending most of the time with the child and can best estimate the child's present behavior and emotional state, whereas biological parents usually have more information to estimate the child's mental health before the traumatic event. It is, however, often difficult to use information from the biological parents for PTSD diagnostics because they may not be available at all, may have no or only limited visiting rights, or may lack solicitude for the child.

This study gives first empirical evidence that there is elevated risk for PTSD in the population of preschool children in foster care. Foster children's PTSS should be acknowledged as one of the consequences of traumatic experiences, and should be included in standard diagnostics when the child enters the child welfare services. Only in this way can all children with elevated PTSS be identified and referred to mental health specialists.

Furthermore, the present study demonstrated that there is a relationship between children's PTSS and foster parental stress. Although the cross-sectional study design did not provide evidence of the direction of this association, these findings still have important practical implications. Regardless whether foster parents' stress elevated children's symptoms or vice versa, welfare services should address this issue when preparing and supporting foster parents for the placement of a traumatized child. Sensitizing foster parents about the consequences of traumatic experiences and promoting their stress management can work in both ways: foster parents would have lower stress levels and so can provide the best conditions for the children to cope with the trauma; conversely, they would react with less distress about their foster children's symptoms. In fact, research has provided support for both pathways and, since the child and the foster parent are interacting, the association is probably reciprocal (Neece, Green, \& Baker, 2012). Further work could usefully apply longitudinal study design to explore the foster family effect on 
recently placed children in order to identify mechanisms for symptom development in the new foster family environment.

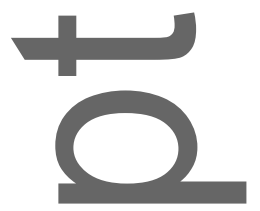

\section{References}

Akaike, H.(1974). A new look at the statistical model identification. IEEE Transactions on

Automatic Control, 19, 716-723.

Alisic, E., Zalta, A. K., Van Wesel, F., Larsen, S. E., Hafstad, G. S., Hassanpour, K., \& Smid, G. E. (2014). Rates of post-traumatic stress disorder in trauma-exposed children and adolescents: Meta-analysis. British Journal of Psychiatry, 204, 335-340.

doi:10.1192/bjp.bp.113.131227

American Psychiatric Association (APA). (2013). Diagnostic and statistical manual of mental disorders (DSM-5). Washington, DC: Author.

Arnold, D. S., O'Leary, S. G., Wolff, L. S., \& Acker, M. M. (1993). The Parenting Scale: A measure of dysfunctional parenting in discipline situations. Psychological

Assessment, 5, 137-144. doi:10.1037/1040-3590.5.2.137

Barnard, J., \& Rubin, D. B. (1999). Small-sample degrees of freedom with multiple imputation. Biometrika, 86, 948-955. doi:10.1093/biomet/86.4.948

Boterhoven de Haan, K. L., Hafekost, J., Lawrence, D., Sawyer, M. G., \& Zubrick, S. R. (2015). Reliability and validity of a short version of the General Functioning subscale of the McMaster Family Assessment Device. Family Process, 54, 116-123.

doi:10.1111/famp.12113

This article is protected by copyright. All rights reserved. 
Domsch, H., \& Lohaus, A. (2010). Elternstressfragebogen [Parental Stress Questionnaire].

Göttingen, Germany: Hogrefe.

Dozier, M., Peloso, E., Lindhiem, O., Gordon, M. K., Manni, M., Sepulveda, S., ... Levine, S.

(2006). Developing evidence-based interventions for foster children: An example of a

randomized clinical trial with infants and toddlers. Journal of Social Issues, 62, 767-

785. doi:10.1111/j.1540-4560.2006.00486.x

Dozier, M.,Zeanah, C. H., \& Bernard, K. (2013). Infants and toddlers in foster care. Child

Development Perspectives, 7, 166-171. doi:10.1111/cdep.12033

Enlow, M. B., Blood, E., \& Egeland, B. (2013). Sociodemographic risk, developmental

competence, and PTSD symptoms in young children exposed to interpersonal

trauma in early life. Journal of Traumatic Stress, 26, 686-694. doi:10.1002/jts.21866

Epstein, N. B., Baldwin, L. M., \& Bishop, D. S. (1983). The McMaster Family Assessment

Device. Journal of Marital and Family Therapy, 9, 171-180. doi:10.1111/j.1752-

0606.1983.tb01497.x

Gewirtz, A. H., DeGarmo, D. S., \& Medhanie, A. (2011). Effects of mother's parenting

practices on child internalizing trajectories following partner violence. Journal of

Family Psychology, 25, 29-38. doi:10.1037/a0022195

Goemans,A., van Geel, M., \& Vedder, P. (2016). Psychosocial functioning in Dutch foster children: The relationship with child, family, and placement characteristics. Child Abuse and Neglect, 56, 30-43. doi:10.1016/j.chiabu.2016.04.006

This article is protected by copyright. All rights reserved. 
Graf, A., Bergstraesser, E., \& Landolt, M. A. (2013). Posttraumatic stress in infants and preschoolers with cancer. Psycho-Oncology, 22, 1543-1548. doi:10.1002/pon.3164 r

Graf, A., Schiestl, C., \& Landolt, M. A. (2011). Posttraumatic stress and behavior problems in infants and toddlers with burns. Journal of Pediatric Psychology, 36, 923-931. doi:1093/jpepsy/jsr021

Haight, W. L., Kagle, J. D., \& Black, J. E. (2003). Understanding and supporting parent-child relationships during foster care visits: Attachment theory and research. Social Work, 48, 195-207. doi:10.1093/sw/48.2.195

Hesse, E., \& Main, M. (2000). Disorganized infant, child, and adult attachment: Collapse in behavioral and attentional strategies. Journal of the American Psychoanalytic Association, 48, 1097-1127. doi:10.1177/00030651000480041101

Kulkarni, M.R, Graham-Bermann, S., Rauch, S. A., \& Seng, J. (2011). Witnessing versus experiencing direct violence in childhood as correlates of adulthood PTSD. Journal of Interpersonal Violence, 26, 1264-1281. doi:10.1177/0886260510368159

Landolt, M.\& Haag, A.-C. (2014). Young Child PTSD Checklist. German version. Zurich, Switzerland: University of Zurich.

Levendosky, A. A., Bogat, G. A., \& Martinez-Torteya, C. (2013). PTSD symptoms in young children exposed to intimate partner violence. Violence Against Women, 19, 187201. doi:10.1177/1077801213476458

This article is protected by copyright. All rights reserved. 
Levendosky, A. A., Huth-Bocks, A. C., Shapiro, D. L., \& Semel, M. A. (2003). The impact of domestic violence on the maternal-child relationship and preschool-age children's functioning. functioning. Journal of Family Psychology, 17, 275-287. doi:10.1037/0893-

3200.17.3.275

(1)

MacKinnon, D. P., Krull, J. L., \& Lockwood, C. M. (2000). Equivalence of the mediation, confounding and suppression effect. Prevention Science, 1, 173-181.

doi:10.1023/A:1026595011371

Meiser-Stedman, R., Dalgleish, T., Glucksman, E., Yule, W., \& Smith, P. (2009). Maladaptive cognitive appraisals mediate the evolution of posttraumatic stress reactions: A 6month follow-up of child and adolescent assault and motor vehicle accident survivors. Journal of Abnormal Psychology, 118, 778-787. doi:10.1037/a0016945

Murray, L., Tarren-Sweeney, M., \& France, K. (2011). Foster carer perceptions of support and training in the context of high burden of care. Child and Family Social Work, 16, 149-158. doi:10.1111/j.1365-2206.2010.00722.x

Naumann, S., Bertram, H., Kuschel, A., Heinrichs, N., Hahlweg, K., \& Döpfner, M. (2010). Der Erziehungsfragebogen (EFB) [The Parenting Scale]. Diagnostica, 56, 144-157. doi:10.1026/0012-1924/a000018

Neece, C. L., Green, S. A., \& Baker, B. L. (2012). Parenting stress and child behavior problems: A transactional relationship across time. American Journal on Intellectual and Developmental Disabilities, 117, 48-66. doi:10.1352/1944-7558-117.1.48

This article is protected by copyright. All rights reserved. 
Orme, J. G., \& Buehler, C. (2001). Foster family characteristics and behavioral and emotional problems of foster children: A narrative review. Family Relations, 50, 3-15. (1) doi:10.1111/j.1741-3729.2001.00003.x

Rosner, R., Arnold, J., Groh, E.-M., \& Hagl, M. (2012). Predicting PTSD from the Child Behavior Checklist: Data from a field study with children and adolescents in foster care. Children and Youth Services Review, 34, 1689-1694.

doi:10.1016/j.childyouth.2012.04.019

Rousseau, C. (2015). Ein Schritt nach vorne? Die Berücksichtigung des Kindes- und Jugendalters bei der Überarbeitung der trauma- und belastungsbezogenen Störungen in DSM-5 und ICD-11 [Stress-related disorders in children and adolescents: A commentary on the revisions of diagnostic criteria in DSM-5 and ICD11]. Kindheit und Entwicklung, 24, 137-145. doi:10.1026/0942-5403/a000169

Scheeringa, M. S. (2011). PTSD in children younger than the age of 13: Toward developmentally sensitive assessment and management. Journal of Child and Adolescent Trauma, 4, 181-197. doi:10.1080/19361521.2011.597079

Scheeringa, M. S. (2013). Young Child PTSD Checklist (YCPC). New Orleans, LA: Tulane

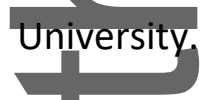

Scheeringa, M. S., Myers, L., Putnam, F. W., \& Zeanah, C. H. (2012). Diagnosing PTSD in early childhood: An empirical assessment of four approaches. Journal of Traumatic Stress, 25, 359-367. doi:10.1002/jts.21723

This article is protected by copyright. All rights reserved. 
Scheeringa, M. S., Myers, L., Putnam, F. W., \& Zeanah, C. H. (2015). Maternal factors as moderators or mediators of PTSD symptoms in very young children: A two-year vrospente prospective study. Journal of Family Violence, 30, 633-642. doi:10.1007/s10896-015$9695-9$

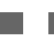

Scheeringa, M. S., \& Zeanah, C. H. (2001). A relational perspective on PTSD in early childhood. Journal of Traumatic Stress, 14, 799-815. doi:10.1023/A:1013002507972

Scheeringa,M. S., \& Zeanah, C. H. (2008). Reconsideration of harm's way: Onsets and comorbidity patterns of disorders in preschool children and their caregivers following Hurricane Katrina. Journal of Clinical Child and Adolescent Psychology, 37, 508-518. doi:10.1080/15374410802148178

Scheeringa, M. S., Zeanah, C. H., Drell, M. J., \& Larrieu, J. A. (1995). Two approaches to the (n) diagnosis of posttraumatic stress disorder in infancy and early childhood. Journal of the American Academy of Child and Adolescent Psychiatry, 34, 191-200.

dol:10.1097/00004583-199502000-00014

Scheeringa, M. S., Zeanah, C. H., Myers, L., \& Putnam, F. W. (2003). New findings on alternative criteria for PTSD in preschool children. Journal of the American Academy of Child and Adolescent Psychiatry, 42, 561-570.

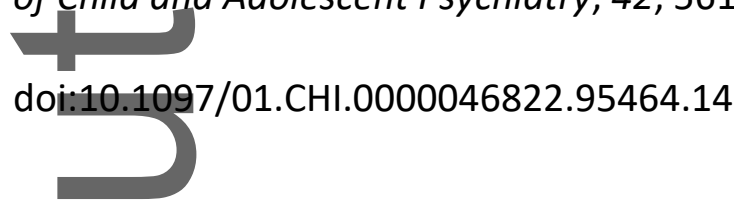

Statistisches Bundesamt. (2016). Statistiken der Kinder- und Jugendhilfe. Erzieherische Hilfe, Eingliederungshilfe für seelisch behinderte Menschen, Hilfe für junge VolljährigeVollzeitpflege [Statistics of the child welfare services. Parenting assistance, 
integration of mentally disabled children, support of young adults-Foster Care].

Wiesbaden, Germany: Author.

Wiesp

Strijker, J., van Oijen, S., \& Knot-Dickscheit, J. (2011). Assessment of problem behaviour by

foster parents and their foster children. Child and Family Social Work, 16, 93-100.

dol:10.1111/j.1365-2206.2010.00717.x

Tagay, S., Repie, N., Düllmann, S., Schlottbohm, E., Hermans, E., Hiller, R., ... Senf, W. (2013).

Traumatische Ereignisse, psychische Belastung und Prädiktoren der PTBS-

Symptomatik bei Kindern und Jugendlichen [Traumatic events, posttraumatic

symptoms, and risk factors in children and adolescents]. Kindheit und Entwicklung,

22, 70-79. doi:10.1026/0942-5403/a000102

Tarren-Sweeney, M. (2008). Retrospective and concurrent predictors of the mental health of children in care. Children and Youth Services Review, 30, 1-25.

doi:10.1016/j.childyouth.2007.05.014

Tarren-Sweeney, M., Hazell, P., \& Carr, V. (2004). Are foster parents reliable informants of children's behaviour problems? Child: Care, Health and Development, 30, 167-175. doi.10.1111/j.1365-2214.2003.00407.x

Tzelgov, J., \& Henik, A. (1991). Suppression situations in psychological research: Definitions, implications, and applications. Psychological Bulletin, 109, 524-536.

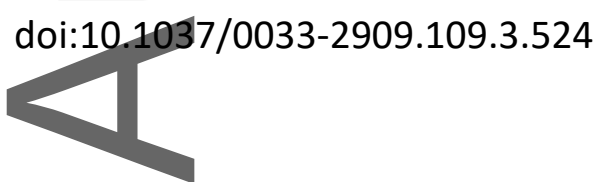

This article is protected by copyright. All rights reserved. 
Van Andel, H., Post, W., Jansen, L., Kamphuis, J., Van der Gaag, R., Knorth, E., \& Grietens, H. (2015). The developing relationship between recently placed foster infants and toddlers toddlers and their foster carers: Do demographic factors, placement characteristics and biological stress markers matter? Children and Youth Services Review, 58, 219226. doi:10.1016/j.childyouth.2015.10.003

Vanderfaeillie, J., Van Holen, F., Vanschoonlandt, F., Robberechts, M., \& Stroobants, T. (2013). Children placed in long-term family foster care: A longitudinal study into the development of problem behavior and associated factors. Children and Youth Services Review, 35, 587-593. doi:10.1016/j.childyouth.2012.12.012

Vasileva, M., \& Petermann, F. (2016). Attachment, development, and mental health in abused and neglected preschool children in foster care: A meta-analysis. Advance ontine publication. Trauma, Violence, and Abuse. doi:10.1177/1524838016669503 Table 1 Sample Characteristics and Traumatic Experiences

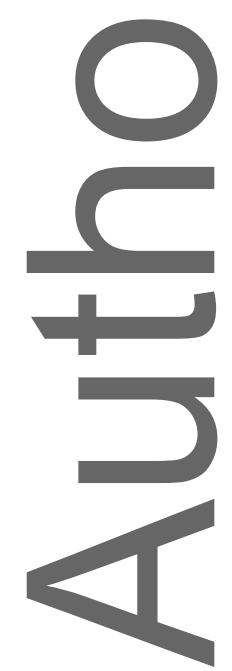

This article is protected by copyright. All rights reserved. 
Note. $N=324$. Displayed are valid percentages without missing values.

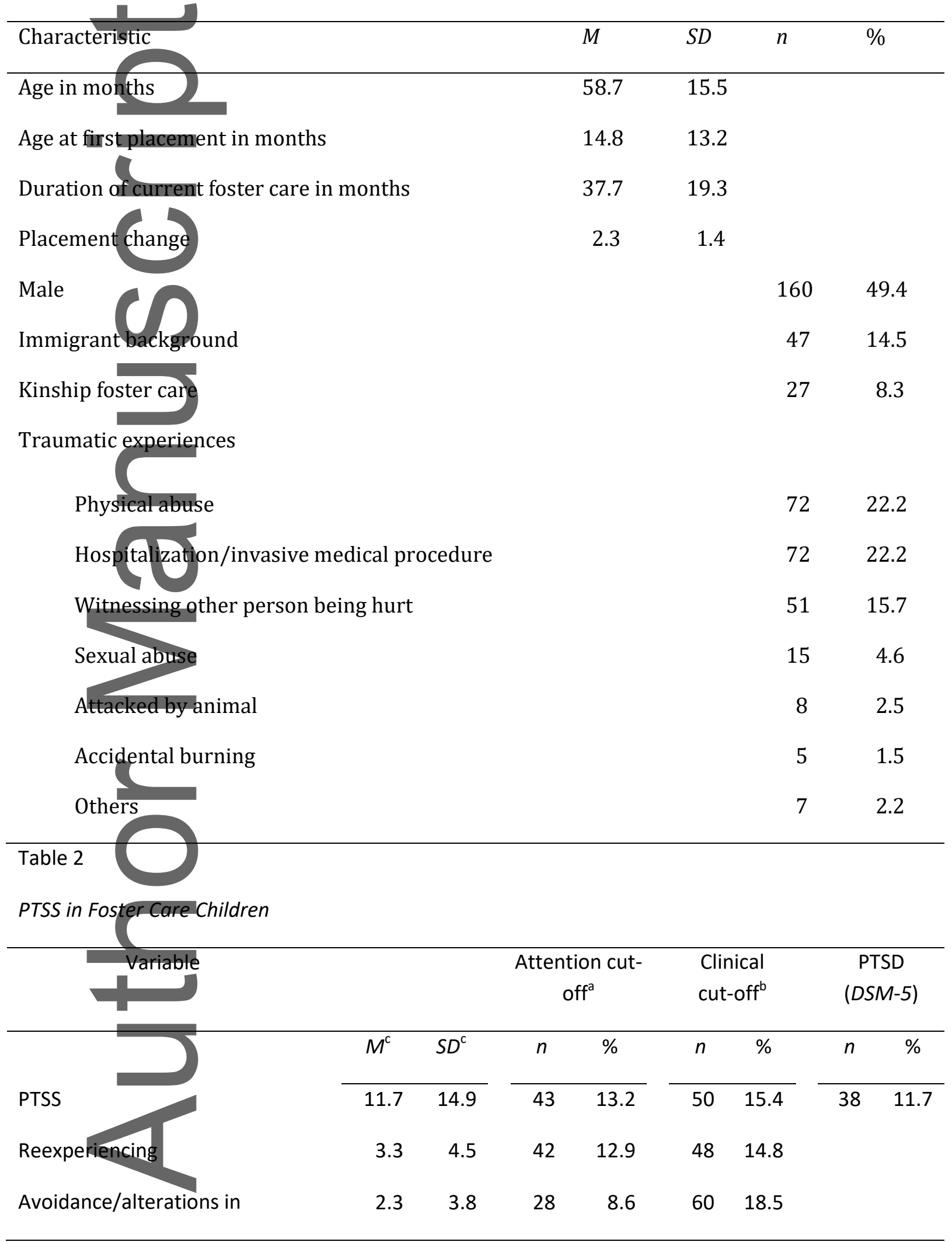

This article is protected by copyright. All rights reserved. 
cognition and mood

Increased arousal

3.6

4.7

51

15.7

42

12.9

Note. $N=324$. PTSS were classified as clinically relevant only if a potentially traumatic experience was reported. PTSS = posttraumatic stress symptoms; DSM-5 = Diagnostic and Statistical Manual of Mental Disorders (5th ed.). (APA, 2013).

${ }^{a}$ Attention cut-offs: Total PTSS $=12$, reexperiencing $=4$, avoidance/negative alterations in cognition and $\operatorname{mood}=2$, increased arousal $=4$; ${ }^{b}$ Diagnosis cut-offs: Total PTSS $=26$, reexperiencing $=8$, avoidance/negative alteration in cognition and mood $=4$, increased arousal $=10 ;{ }^{c} n=147$

Table 3

Spearmen's Correlation Between the Variables of Interest

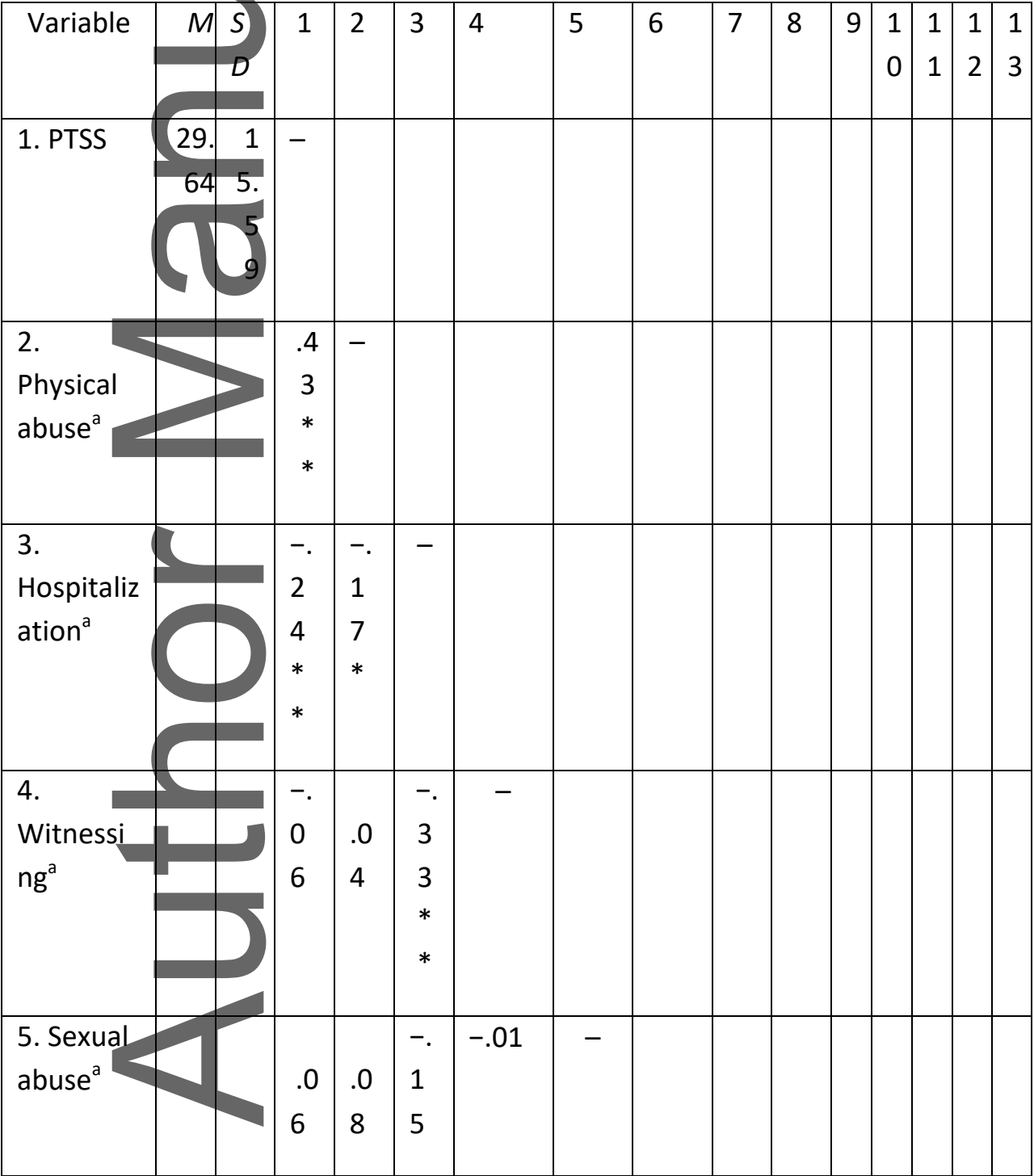

This article is protected by copyright. All rights reserved. 


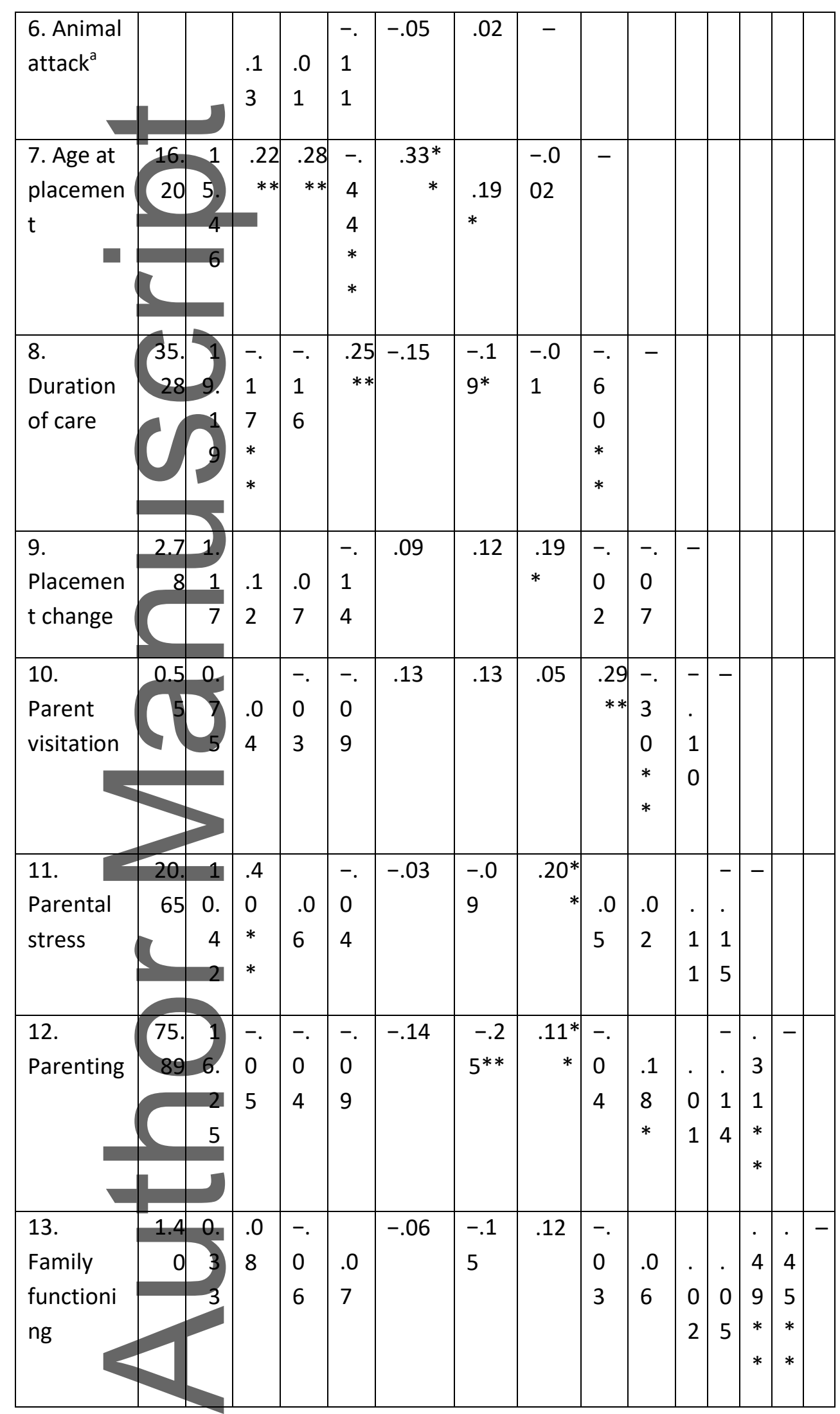

Note. $N=147$.

This article is protected by copyright. All rights reserved. 
${ }^{a}$ Dichotomous variable.

${ }^{*} p<.05 .{ }^{* *} p<.01$.

Table 4

(r)

Final Model of the Regression Analysis Predicting PTSS Severity

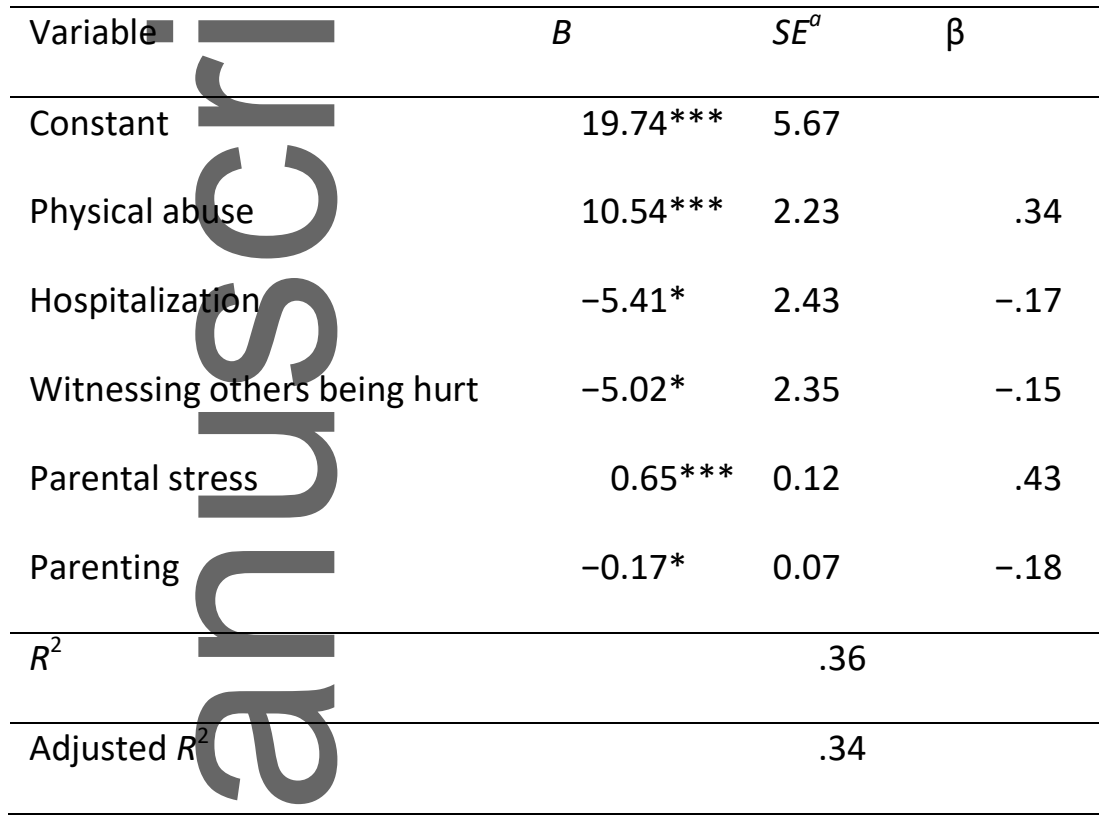

Note. $N=147$.

${ }^{a}$ Standard errors based on 1,000 bootstrapped samples.

${ }^{*} p<.05 . * * * p<.001$.

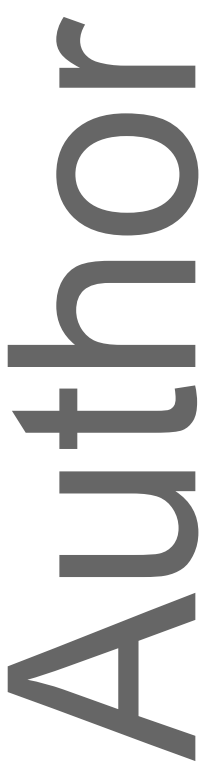

This article is protected by copyright. All rights reserved. 


\section{University Library}

\section{- M M I N E R VA A gateway to Melbourne's research publications}

Minerva Access is the Institutional Repository of The University of Melbourne

Author/s:

Vasileva, M;Petermann, F

Title:

Posttraumatic Stress Symptoms in Preschool Children in Foster Care: The Influence of Placement and Foster Family Environment

Date:

2017-10-01

Citation:

Vasileva, M. \& Petermann, F. (2017). Posttraumatic Stress Symptoms in Preschool Children in Foster Care: The Influence of Placement and Foster Family Environment. JOURNAL OF TRAUMATIC STRESS, 30 (5), pp.472-481. https://doi.org/10.1002/jts.22217.

Persistent Link:

http://hdl.handle.net/11343/293537 